\section{Expressão das Proteinas p19 (gag) e gp21 (env) do HTLV-1 no Tecido Tiveoideano de Pacientes com Doença Auto-Imune da Tiveóide e no Tecido Tiveoideano Normal}

\section{RESUMO}

As doenças auto-imunes da tireóide são o resultado da quebra da autotolerância causada principalmente por fatores genéticos e ambientais. O retrovírus HTLV-1 tem sido implicado como um importante fator ambiental desencadeador destas doenças. Objetivando encontrar evidências da participação deste retrovírus, 47 tecidos tireoideanos parafinados de 45 pacientes com doença de Graves e dois com tireoidite de Hashimoto, juntamente com tecidos tireoideanos normais de seis tireóides obtidas após necropsia e linfonodo de paciente com infecção pelo HTLV-1, utilizados como controles negativo e positivo, respectivamente, foram estudados. Com a intenção de detectar as proteínas p19 (gag) e gp21 (env) do HTLV-1, os tecidos foram submetidos a imuno-histoquímica, utilizando-se um novo método de recuperação antigênica e anticorpos monoclonais anti-p19 e anti-gp21. Como resultado obtivemos a mediana do percentual de positividade no sexo feminino de $30 \%$ e $41 \%$, no masculino de $27 \%$ e $52 \%$ e total de $30 \%$ e $41 \%$, para as proteínas p19 e gp21, respectivamente. Nos tecidos tireoideanos normais, cinco foram positivos para as duas proteínas e apresentaram mediana do percentual de positividade de $17 \%$ para a p19 e $39 \%$ para a gp 21 . A detecção das proteinas p19 e gp21 no tecido tireoideano de pacientes com doença auto-imune da tireóide e em tecidos normais talvez indique a expressão genética de seqüências do HTLV-1 integradas ao genoma dos indivíduos estudados, ou talvez possa representar mimetismo molecular, ou reação cruzada, causada pela presença de antígenos comuns entre as proteínas p19 e gp21 do HTLV-1 e as células epiteliais foliculares da tireóide. (Arq Bras Endocrinol Metab 2000;44/5: 417-424)

Unitermos: Doença de Graves; Tireoidite de Hashimoto; HTLV-1; Doença auto-imune da tireóide; Retrovirose endógena

\footnotetext{
ABSTRACT

Autoimmune thyroid diseases are the result of the breakdown of self-tolerance caused mainly by genetic and environmental factors. Retrovirus HTLV-1 has been implied as an important environmental factor causing these diseases. In order to obtain evidences of the participation of this retrovirus, 47 paraffin embedded thyroid tissues from 45 patients with Graves' disease and two with Hashimoto's thyroiditis were studied, together with six normal thyroid tissues obtained from autopsies and lymph node tissue from a patient infected with the HTLV-1, used as negative and positive controls, respectively. All tissues were submitted to immunohistochemistry for the detection of protein p19 (gag) and gp21 (env) of the HTLV-1, using a new antigen retrieval method and anti-p19 and anti-gp21 monoclonal antibodies. The median positivity percentage for proteins p19 and gp21 were, respectively: $30 \%$ and $41 \%$ (for females), $27 \%$ and $52 \%$ (for males) and $30 \%$ and $41 \%$ (for all). Five out of 6 normal thyroid tissues were positive for both proteins, with a median positivity percentage of $17 \%$ for $p 19$ and $39 \%$ for gp 21 . Detection of proteins $p 19$ and gp21 in thyroid tissues from patients with autoimmune thyroid diseases and in normal thyroid tissues might indicate the expression of
}

\section{artigo original}

\author{
Rubens A.C. Filbo \\ Mário Vaisman \\ Enói A.G. Vilar \\ Eliene C. Fonseca
}

\begin{abstract}
Disciplina de Endocrinologia, Departamento de Medicina Clinica (RACF), Departamento de Patologia (EAGV) e Laboratório de ImunoHistoquímica e Hibridização in situ, Departamento de Patologia (ECF), Universidade Federal Fluminense, Niterói, RJ e Disciplina de Endocrinologia, Departamento de Medicina Clínica, Universidade Federal do Rio de Janeiro (MV), Rio de Janeiro, $R J$
\end{abstract}

Recebido em 22/11/99 Revisado em 22/03/00 Aceito em 12/05/00 
genetic sequences of HTLV-1 integrated into the genome of these individuals or may represent molecular mimicry and cross-reaction caused by the presence of shared antigens between HTLV-1 proteins p19 and gp21 and thyroid follicular epithelial cells. (Arq Bras Endocrinol Metab 2000;44/5: 417-424)

Keywords: Graves' disease: Hashimoto's thyroiditis; HTLV-1; Autoimmune thyroid disease; Endogenous retroviruse

$\mathrm{A}$ S DOENÇAS AUTO-IMUNES DA TIREOIDE são o resultado da quebra da auto-tolerância num indivíduo geneticamente predisposto, causadas por um fator desencadeador (1). O retrovírus HTLV-1 vem sendo atualmente implicado como um importante fator ambiental desencadeador destas doenças, como relatado em estudos recentes que demonstram a associação da infecção pelo HTLV-1 e o desenvolvimento de doenças auto-imunes da tireóide (2-5).

A associação entre infecção e doenças autoimunes, especialmente infecções virais, não tem sido incomum. No caso do diabetes mellitus tipo 1, existe uma relação temporal após o início de certas infecções virais e o aparecimento desta doença auto-imune. Isto aconteceu na Suécia (6) e no estado de Nova Iorque (7) com infecções pelos vírus coxsackie B e da caxumba, respectivamente. $\mathrm{O}$ mesmo ocorreu, como relatado por Jaspan e cols. (8), relacionado com auto-imunidade tireoideana, quando foi evidenciada correlação entre a infecção por um retrovírus e o aumento do número de casos da doença de Graves em uma comunidade de Nova Orleans. Já em Nice, na França, dois casos de tireoidite de Hashimoto foram detectados em pacientes com hepatite crônica ativa (9).

Mas, como poderiam estes agentes infecciosos levar à doença auto-imune da tireóide? Na verdade, vários mecanismos são propostos para explicar a indução da auto-imunidade pela infecção; entretanto, parece que somente três possibilidades seriam importantes entre os indivíduos susceptiveis a desenvolverem doença autoimune da tireóide: - infecção direta das células tireoideanas com estímulo de células $\mathrm{T}$ e liberação de citocinas, levando à indução do antígeno de classe II do complexo maior de histocompatibilidade (MHC); mimetismo molecular com auto-antígenos e indução de auto-anticorpos e ativação de células $\mathrm{T}$ auto-reativas $\mathrm{e}$ ativação policlonal de células $T$, incluindo subpopulações de células $T$ auto-reativas, por um superantígeno endógeno ou, mesmo, um organismo infeccioso (10). Parece razoável presumir que os três mecanismos possam operar simultaneamente no mesmo indivíduo, ou separadamente, em indivíduos diferentes.
Com a intenção de obter evidências da provável participação do retrovírus HTLV-1 no desenvolvimento das doenças auto-imunes da tireóide, nós investigamos a presença das proteínas p19 (gag) e gp21 (env) deste retrovírus em 47 tecidos parafinados obtidos da tireóide de 45 pacientes com a doença de Graves e dois com tireoidite de Hashimoto.

\section{MATERIAL E MÉTODOS}

\section{Tecidos}

Blocos de tecido tireoideano parafinados de 45 pacientes com doença de Graves e dois com tireoidite de Hashimoto foram analisados em lâminas coradas pela hematoxilina e eosina (HE), com a intenção de selecionar o bloco de tecido parafinado que apresentasse a maior intensidade de infiltração mononuclear, desde que queríamos estudar a parte do tecido mais envolvida pelo processo auto-imune. A intensidade de infiltração mononuclear foi quantificada pela seguinte classificação: $(0+)$ sem infiltração; $(1+)$ poucos mononucleares isolados no tecido; $(2+)$ pequenas áreas de infiltração mononuclear; (3+) áreas médias de infiltração mononuclear e (4+) grandes áreas de infiltração mononuclear, com ou sem formação de folículos linfóides. Quando não existia infiltração mononuclear $(0+)$, eram escolhidos os blocos com maior quantidade de tecido. Como controle positivo foram utilizadas secções de um linfonodo de paciente com infecção pelo HTLV-1 e, como controle negativo, tecidos tireoideanos normais de seis tireóides obtidas após necropsia.

\section{Imuno-Histoquímica}

Todos os 47 tecidos dos pacientes com doença autoimune da tireóide e os tecidos controles foram investigados para a expressão das proteínas p19 e gp21 através dos anticorpos monoclonais anti-p19 e anti-gp21. As seç̧ões com $4 \mathrm{~mm}$ eram desparafinadas, reidratadas e a atividade da peroxidase endógena era suprimida através da imersão em 3 banhos consecutivos de 15, 20 e novamente 20 minutos, com $20 \mathrm{ml}$ de $\mathrm{H}_{2} \mathrm{O}_{2}$ (PA REAGEN) mais $180 \mathrm{ml}$ de metanol a $70 \%$, sendo as secções lavadas com TRIS (TRIS/HCl, 0,05M, pH $7,4)$ no intervalo de cada imersão. Após a supressão da peroxidase endógena, $600 \mathrm{ml}$ de tampão citrato de sódio $(10 \mathrm{mM}, \mathrm{pH} 6,0)$ eram aquecidos em panela de pressão de microondas aberta, por 15 minutos, dentro de um forno de microondas a $700 \mathrm{~W}$. As seç̧ões eram então colocadas na panela de pressão de microondas imersas no tampão citrato aquecido e a panela ia ao forno de microondas, fechada por 10 minutos, a $560 \mathrm{~W}$, com a intenção de intensificar o resultado da 
imuno-histoquímica (recuperação antigênica) (11). Após retiradas da panela de pressão, as seç̧ões eram lavadas com TRIS e incubadas com $20 \mathrm{mg} \%$ de tripsina (Sigma) $+134 \mathrm{mg}$ de cloreto de cálcio $+100 \mathrm{ml}$ de TRIS por 5 minutos, na temperatura ambiente, para digestão enzimática. Novamente as secções eram lavadas com TRIS e para se evitar ligações não específicas, eram incubadas por uma noite com leite desnatado mais TBS (TRIS/ $\mathrm{HCl} 0,05 \mathrm{M}+\mathrm{NaCl} 0,5 \mathrm{M}, \mathrm{pH} 7,6$ )

Os anticorpos monoclonais primários anti-p19 (Du Pont - NEA 9279 / PA 149 - contra os resíduos de aminoácidos 114-130 da p19 (gag) do HTLV-1 diluído 1:100) e anti-gp21 (Du Pont - NEA 9278 / PA 331 - contra os resíduos de aminoácidos 414-440 da gp21 (env) do HTLV-1 - diluído 1:100) eram incubados sobre as secções por 40 minutos, na temperatura ambiente. As secções eram então lavadas 3 vezes com TRIS, 10 minutos cada lavagem. $\mathrm{O}$ anticorpo secundário de cabra contra imunoglobulinas de coelho e camundongo, associado com moléculas de peroxidase polimerizada, ENVISION System (DAKO CORPORATION - Carpinteria, CA), era incubado sobre as secções por 40 minutos na temperatura ambiente e, mais tarde, as secções eram lavadas 3 vezes com TRIS, 10 minutos cada lavagem. A revelação era feita através da incubação com substrato cromogênico, que consistia de $\mathrm{H}_{2} \mathrm{O}_{2} 10$ Volume $2 \mathrm{ml}+$ Diaminobenzidina (DAB - SIGMA) $5 \mathrm{mg} / 10 \mathrm{ml}$ + TRIS $100 \mathrm{ml}$, por 3 a 5 minutos. As secções eram contra-coradas com hematoxilina de Mayers. $O$ processo de desidratação e montagem das lâminas era feito através da lavagem com $\mathrm{H}_{2} \mathrm{O}$ destilada e imersão no álcool $90 \%$ por 1 a 2 minutos, álcool a $99 \%$ por 1 a 2 minutos e 3 vezes no xilol também por 1 a 2 minutos, sendo então montadas com bálsamo do Canadá.

\section{Análise da Imuno-Histoquímica}

$O$ resultado da imuno-histoquímica foi analisado utilizando-se um microscópio óptico Zeiss acoplado a uma câmera de vídeo (JVC TK-1270), objetiva 40X, conectados a um computador Pentium de $133 \mathrm{MHz}$ e monitor de 17 polegadas. As lâminas com as secções eram posicionadas no microscópio e as imagens capturadas e analisadas através do software KS 300 versão 2.0 (Kontron Elektronik). Foram capturados 10 campos por seç̧ão, de forma aleatória, e cada um dos 10 campos capturados foi analisado utilizando-se um grid com 24 retângulos (cada retângulo com $625 \mu \mathrm{m}^{2}$ de área), optando-se por analisar 12 retângulos (área total analisada em cada campo capturado igual a $7500 \mu \mathrm{m}^{2}$ ), sendo escolhidos retângulo sim e não em seqüência. De cada retângulo "sim" eram contadas todas as célu- las, incluindo-se aquelas que estivessem em contato com as linhas da esquerda e a de baixo e excluindo-se as que estivessem em contato com as linhas de cima e da direita. Após contadas todas as células nos retângulos "sim", eram então contadas as células positivas nestes retângulos e posteriormente calculado o percentual de positividade de cada secção.

\section{Análise Estatística}

Os únicos testes aplicados foram: o não paramétrico de Kruskal-Wallis e o de comparações múltiplas baseado na estatística de Kruskal-Wallis, utilizados na comparação do percentual de positividade por grupos de infiltração mononuclear. $\mathrm{O}$ nível de significância adotado foi de $5 \%(0,05)$.

\section{RESULTADOS}

Todos os 47 tecidos tireoideanos dos pacientes com a doença de Graves e a tireoidite de Hashimoto, além dos controles, foram estudados individualmente procurando-se avaliar o percentual de positividade para cada uma das proteínas estudadas do HTLV-1 (p19 e gp21). Na tabela 1 podemos observar o percentual de positividade de cada paciente estudado e a intensidade de infiltração mononuclear na HE.

Foram $39(82,9 \%)$ pacientes positivos para a p19 e $40(85,1 \%)$ para a gp21. Cinco $(10,6 \%)$ foram somente positivos para a p19, como também seis $(12,7 \%)$ somente para a gp 21 . Somente dois $(4,2 \%)$ pacientes foram negativos para as duas proteínas e 34 $(72,3 \%)$ positivos para as duas proteínas simultaneamente. Entre os pacientes negativos para as duas proteínas, um era do sexo feminino e um do sexo masculino. Já os positivos para as duas proteínas simultaneamente, $10(29,4 \%)$ eram do sexo masculino e 24 $(70,5 \%)$ do sexo feminino. Dos cinco que foram positivos somente para a p19 todos eram do sexo feminino. Da mesma forma, entre os seis somente positivos para a gp21, dois $(33,3 \%)$ eram do sexo masculino e quatro $(66,6 \%)$ do sexo feminino.

A mediana do percentual de positividade das proteínas $\mathrm{p} 19$ e gp21 foi semelhante quando comparados o sexo feminino e o total, provavelmente pelo grande número de tecidos oriundos de pacientes do sexo feminino na amostra. Não houve significância estatística quando analisados os sexos entre si e cada um com o total.

O critério definido para escolha do bloco de tecido parafinado que seria utilizado na imuno-histoquímica era naquele que pela análise das lâminas coradas com $\mathrm{HE}$, utilizando-se a microscopia óptica, apresentasse a maior intensidade de infiltração mononuclear. Caso não 
Tabela 1. Percentual de positividade e infiltração mononuclear de cada paciente.

\begin{tabular}{|c|c|c|c|c|c|}
\hline PAC. & SEXO & DOENÇA & $\begin{array}{l}\text { p19 } \\
(\%)\end{array}$ & $\begin{array}{c}\text { gp21 } \\
(\%)\end{array}$ & $\begin{array}{l}\text { INFILTRAÇĀO } \\
\text { (HE) }\end{array}$ \\
\hline 1 & $F$ & Graves & 28 & 47 & $1+$ \\
\hline 2 & $\mathrm{~F}$ & Graves & 35 & 47 & $3+$ \\
\hline 3 & $F$ & Graves & 37 & 0 & $3+$ \\
\hline 4 & $\mathrm{~F}$ & Graves & 20 & 76 & $\mathrm{O}_{+}$ \\
\hline 5 & $\mathrm{~F}$ & Graves & 30 & 56 & $1+$ \\
\hline 6 & $\mathrm{~F}$ & Graves & 56 & 87 & $0_{+}$ \\
\hline 7 & $\mathrm{~F}$ & Hashimoto & 34 & 29 & $3+$ \\
\hline 8 & $\mathrm{~F}$ & Graves & 24 & 31 & $3+$ \\
\hline 9 & $\mathrm{~F}$ & Graves & 29 & 13 & $4+$ \\
\hline 10 & $\mathrm{~F}$ & Graves & 48 & 11 & $1+$ \\
\hline 11 & $\mathrm{~F}$ & Graves & 5 & 30 & $4+$ \\
\hline 12 & $M$ & Graves & 27 & 64 & $1+$ \\
\hline 13 & $\mathrm{~F}$ & Graves & 0 & 24 & $3+$ \\
\hline 14 & $M$ & Graves & 16 & 38 & $4+$ \\
\hline 15 & $\mathrm{~F}$ & Graves & 15 & 7 & $3+$ \\
\hline 16 & $\mathrm{~F}$ & Graves & 13 & 0 & $4+$ \\
\hline 17 & $\mathrm{~F}$ & Graves & 46 & 41 & $2+$ \\
\hline 18 & $\mathrm{~F}$ & Graves & 0 & 12 & $1+$ \\
\hline 19 & $\mathrm{~F}$ & Graves & 0 & 0 & $2+$ \\
\hline 20 & $M$ & Graves & 0 & 0 & $1+$ \\
\hline 21 & $\mathrm{~F}$ & Graves & 28 & 0 & $1+$ \\
\hline 22 & $\mathrm{~F}$ & Graves & 39 & 48 & $3+$ \\
\hline 23 & $\mathrm{~F}$ & Graves & 0 & 40 & $1+$ \\
\hline 24 & $\mathrm{~F}$ & Graves & 85 & 86 & $1+$ \\
\hline 25 & $\mathrm{~F}$ & Graves & 52 & 60 & $2+$ \\
\hline 26 & $\mathrm{~F}$ & Graves & 35 & 35 & $1+$ \\
\hline 27 & $M$ & Graves & 41 & 64 & $2+$ \\
\hline 28 & F & Graves & 38 & 60 & $1+$ \\
\hline 29 & $\mathrm{M}$ & Graves & 43 & 54 & $\mathrm{O}_{+}+$ \\
\hline 30 & $M$ & Graves & 23 & 57 & $2+$ \\
\hline 31 & $\mathrm{M}$ & Graves & 0 & 25 & $1+$ \\
\hline 32 & $M$ & Graves & 31 & 71 & $0_{+}$ \\
\hline 33 & M & Graves & 54 & 54 & $\mathrm{O}_{+}$ \\
\hline 34 & $\mathrm{~F}$ & Graves & 56 & 55 & $1+$ \\
\hline 35 & $\mathrm{~F}$ & Graves & 32 & 60 & $1+$ \\
\hline 36 & $M$ & Graves & 37 & 36 & $3+$ \\
\hline 37 & $\mathrm{~F}$ & Graves & 33 & 42 & $3+$ \\
\hline 38 & $\mathrm{~F}$ & Hashimoto & 51 & 57 & $3+$ \\
\hline 39 & $\mathrm{~F}$ & Graves & 1 & 41 & $1+$ \\
\hline 40 & $\mathrm{~F}$ & Graves & 41 & 75 & $0+$ \\
\hline 41 & $M$ & Graves & 34 & 28 & $1+$ \\
\hline 42 & $M$ & Graves & 16 & 33 & $3+$ \\
\hline 43 & F & Graves & 14 & 56 & $4+$ \\
\hline 44 & $M$ & Graves & 0 & 52 & $0_{+}+$ \\
\hline 45 & $\mathrm{~F}$ & Graves & 0 & 59 & $1+$ \\
\hline 46 & $\mathrm{~F}$ & Graves & 48 & 0 & $\mathrm{O}_{+}$ \\
\hline 47 & $\mathrm{~F}$ & Graves & 27 & 0 & $4+$ \\
\hline
\end{tabular}

houvesse infiltração mononuclear, a escolha recaia sobre o bloco com maior quantidade de tecido.

$\mathrm{Na}$ tabela 2 temos a mediana do percentual de positividade das proteínas $\mathrm{p} 19$ e gp21 por grupos de infiltração mononuclear. $O$ que nos chamou a atenção foi a tendência para um alto percentual de positividade nos tecidos com baixa infiltração mononuclear, especialmente naqueles sem infiltração $(0+)$, tanto para a p19, quanto para a gp21, mas de forma bastante intensa para esta proteína (62\%). Por outro lado, nos grupos com muita infiltração mononuclear $(3+, 4+)$, observamos exatamente o oposto, ou seja, um baixo percentual de positividade para as duas proteínas, com destaque para o grupo onde havia infiltração mononuclear intensa (4+). A relação entre a mediana do percentual de positividade da p19 e gp21 e os grupos de intensidade da infiltração mononuclear, foi feita através dos testes mencionados. Para melhor distribuição dos grupos de intensidade de infiltração mononuclear, devido ao pequeno número de pacientes nos grupos $(2+)$ e (4+), foi necessário uma redistribuição, ficando então distribuídos para efeito de comparação como na tabela 3. Não houve diferença significativa quando comparados os três grupos de infiltração mononuclear $[(0+)$, 
Tabela 2. Mediana do percentual de positividade das proteinas p19 e gp21 por grupos de infiltração mononuclear.

\begin{tabular}{cccc}
\hline $\begin{array}{c}\text { Grupos de } \\
\text { Infiltração (HE) }\end{array}$ & $\begin{array}{c}\text { Paciente } \\
\mathbf{n}(\%)\end{array}$ & $\begin{array}{c}\text { p19 } \\
\text { mediana (variação) }\end{array}$ \\
\hline O+ & $8(17,1)$ & $42 \%(0-56 \%)$ & gp21 \\
$1+$ & $17(36,1)$ & $28 \%(0-85 \%)$ & $41 \%(0-86 \%)$ \\
$2+$ & $5(10,6)$ & $41 \%(0-52 \%)$ & $57 \%(0-64 \%)$ \\
$3+$ & $11(23,4)$ & $34 \%(0-51 \%)$ & $32 \%(0-57 \%)$ \\
$4+$ & $6(12,7)$ & $15 \%(5-29 \%)$ & $22 \%(0-56 \%)$ \\
\hline Total & $47(100)$ & $30 \%(0-85 \%)$ & $41 \%(0-87 \%)$ \\
\hline
\end{tabular}

Tabela 3. Redistribuição dos grupos de intensidade de infiltração mononuclear e mediana do percentual de positividade das proteínas p19 e gp21.

\begin{tabular}{cccc}
\hline Grupos de Infiltraçāo & Pacientes & p19 & gp21 \\
(HE) & $\mathbf{n}(\%)$ & mediana (variação) & mediana (variaçāo) \\
$(0+)$ & $8(17,1)$ & $42 \%(0-56 \%)$ & $62 \%(0-87 \%)$ \\
$(1+, 2+)$ & $22(46,8)$ & $29 \%(0-85 \%)$ & $44 \%(0-86 \%)$ \\
$(3+, 4+)$ & $17(36,1)$ & $27 \%(0-51 \%)$ & $31 \%(0-57 \%)$ \\
\hline
\end{tabular}

$(1+, 2+)$ e $(3+, 4+)], p=0,24$, e a mediana do percentual de positividade da $\mathrm{p} 19$. Por outro lado, ocorreu diferença significativa, $p=0,02$, quando comparados os grupos de infiltração mononuclear com a mediana do percentual de positividade da gp21. A mediana do percentual de positividade da gp21 no grupo sem infiltração $\left(0_{+}\right)$diferiu significativamente do grupo com infiltração $(3+$ e $4+)$.

O tecido linfóide oriundo de paciente infectada pelo HTLV-1 e com doença provocada por este retrovírus, utilizado como controle positivo, ficou intensamente marcado tanto para a p 19, quanto para a gp21, com um nível de marcação não visto nos tecidos tireoideanos.
Nos seis tecidos tireoideanos normais utilizados como controle negativo, surpreendentemente, foi encontrada positividade simultânea para ambas as proteínas em cinco $(83,3 \%)$. A mediana do percentual de positividade foi de $17 \%(0-23 \%)$ para a p19 e $39 \%(0-56 \%)$ para a gp2 1 .

A positividade nos tecidos de pacientes com doença auto-imune da tireóide, como também nos tecidos normais, caracterizou-se pela coloração do núcleo da célula folicular pelo pigmento acastanhado característico da peroxidase, somente marcando o citoplasma para a gp21 em poucos tecidos, mostrando que as proteínas p19 e gp21 são predominantemente intracelulares, como podemos observar na figura 1.

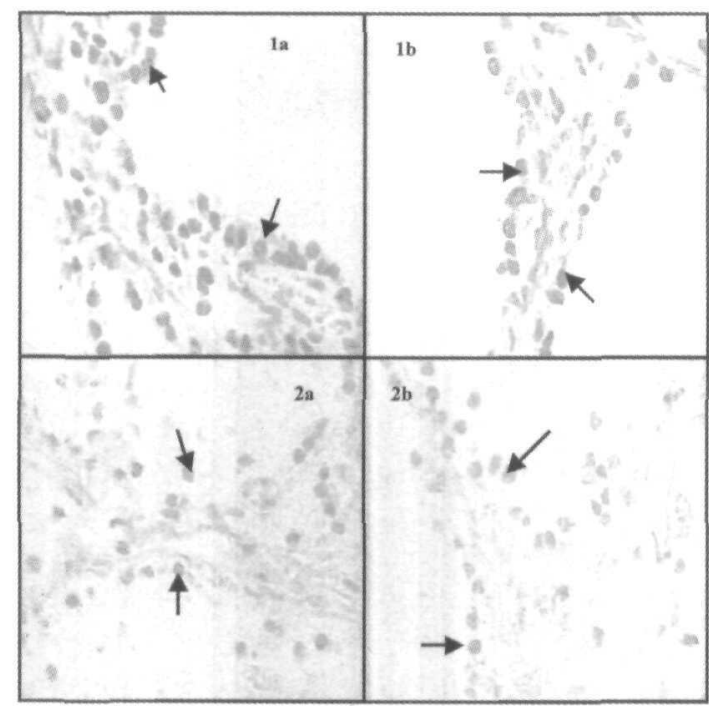

Figura 1. Imuno-histoquímica do tecido tireoideano com a marcação característica do núcleo (setas). (1a) p19 e (1b) gp21 no paciente 34. (2a) p19 e (2b) gp21 no tecido normal. (X400). 


\section{DISCUSSĀO}

As doenças auto-imunes ocorrem somente num "ambiente" geneticamente predisposto (1). Entretanto, a existência da predisposição genética não é o único fator necessário para o desenvolvimento da auto-imunidade patológica. Certamente, a existência de um fator desencadeante é essencial para o desenvolvimento das doenças auto-imunes. O retrovírus HTLV-1 tem sido implicado como um fator desencadeador das doenças auto-imunes da tireóide (2-5) e a evidência de sua presença, ou somente a detecção de seqüências genéticas, no tecido tireoideano de pacientes com doenças auto-imunes da tireóide, pode implicar de forma direta este retrovírus no processo de desenvolvimento da auto-imunidade tireoideana (12-15).

A região tax do genoma do HTLV-1 está fortemente relacionada com a transativação de genes responsáveis por citocinas, especificamente a IL-2, e outras proteínas celulares implicadas na amplificação e interferência com a resposta imune (16). Um importante produto da região tax é o fator inibitório da apoptose mediado pelo Fas, que bloqueia a deleção de células $\mathrm{T}$ periféricas auto-reativas, comprometendo a auto-tolerância. Kishi e cols. (17) mostraram que camundongos transgênicos com a expressão da região env-px do HTLV-1 tinham alta incidência de artropatia auto-imune e resistência para a apoptose das células $\mathrm{T}$ periféricas mediada pelo Fas. Como podemos ver, a relação entre as células do hospedeiro e o HTLV-1 é mais complexa do que parece e a infecção (presença do vírus), ou somente a presença de parte do genoma do vírus, poderia ativar o processo de auto-imunidade patológica num indivíduo geneticamente predisposto.

Apesar da detecção das proteinas p19 e gp21 do HTLV-1 em respectivamente $83 \%$ e $85 \%$ dos pacientes estudados, nenhum deles tinha história ou qualquer evidência de infecção pelo HTLV-1. Entretanto, a presença destas proteínas no tecido tireoideano de pacientes com doença auto-imune da tireóide pode diretamente implicar este retrovírus no desenvolvimento da auto-imunidade patológica. Kawai e cols. (12), detectaram a proteína gp46 (env) do HTLV-1 através da imuno-histoquímica e parte do genoma do retrovírus, usando a hibridização in situ e a $\mathrm{PCR}$, no tecido tireoideano de um paciente infectado com o HTLV-1 que desenvolveu a tireoidite de Hashimoto. O que significa a presença de proteínas do HTLV-1 no tecido tireoideano de pacientes com doença autoimune da tireóide? No tecido tireoideano de pacientes infectados pelo HTLV-1, isso pode significar que este é um dos tecidos corporais pelo qual o retrovírus tem predileção e, em indivíduos geneticamente predispostos, pode de forma direta, causar doença auto-imune por exposição de auto-antígenos (16). Por outro lado, a presença de proteínas do HTLV-1 (p19 e gp21) no tecido tireoideano de pacientes sem qualquer evidência de infecção por este retrovírus, talvez indique a existência de uma retrovirose endógena, como sugerido por Shattles e cols. (18), quando detectaram a proteína p19 do HTLV-1 em secções de glândula salivar labial de pacientes com a síndrome de Sjögren, sem a evidência de infecção pelo HTLV-1.

As retroviroses endógenas, que são transmitidas verticalmente como elementos Mendelianos estáveis, parecem já comprometer mais do que $1 \%$ do DNA humano (19). O que levanta a possibilidade de as proteínas p19 e gp21 do HTLV-1 encontradas no tecido tireoideano de pacientes com doença auto-imune da tireóide e, especialmente, no tecido tireoideano normal, poder representar a expressão de retrovirose endógena.

Os retrovírus endógenos são vírus parciais ou completos que se incorporam ao DNA do hospedeiro, adquirindo a condição de poder ser transmitidos para gerações futuras, mas perdendo a capacidade de infectar ou de causar doença (20). Brookes e cols. (21) estudaram a expressão de uma seqüencia endógena relacionada ao HTLV-1, chamada de HRES-1 $(22,23)$, que é capaz de codificar as proteínas p15 e p25 e tem $20-40 \%$ de homologia com a região gag dos retrovírus HIV-2, HTLV-1 e HTLV-2 e, ainda, 33\% de similaridade com a proteina $\mathrm{p} 19$ do HTLV-1 nas glândulas salivares labiais de pacientes com a síndrome de Sjögren e em glândulas salivares normais. Eles encontraram o HRES-1 tanto no tecido normal quanto no acometido pela doença auto-imune. Em nosso estudo, também encontramos positividade para a p19 e gp'21, simultaneamente, no tecido tireoideano normal $(83,3 \%)$ em cinco das seis glândulas estudadas.

A presença das proteínas p19 e gp21 do HTLV1 nunca havia sido investigada no tecido tireoideano de pacientes com doença auto-imune da tireóide, ou no tecido tireoideano normal. Somente a proteína gp46 (env) do HTLV-1 foi detectada no tecido tireoideano de um paciente infectado pelo retrovírus e que desenvolveu tireoidite de Hashimoto (12). Outro aspecto importante de nosso estudo é o fato de que nenhum dos pacientes estudados apresentava qualquer evidência de infecção pelo retrovírus, o que torna a detecção dessas proteínas do HTLV-1, no tecido tireoideano, um importante achado, especialmente quando levamos em consideração o que poderia desencadear as doenças auto-imunes da tireóide. Quando analisamos o alto percentual de positividade para as 
proteínas p19 e gp21 encontrado nos tecidos de pacientes com doença auto-imune da tireóide, como também nos tecidos normais, não podemos deixar de pensar na possibilidade de reação cruzada, ou mesmo de mimetismo molecular, entre as proteínas p19 (gag) e gp21 (env) do HTLV-1 e proteínas expressas no tecido tireoideano. A proteína p19 tem sido detectada no tecido sinovial de pacientes com artrite reumatóide, mas sem avaliação no tecido sinovial normal (24), nas glândulas salivares labiais de pacientes com a síndrome de Sjögren, como também em glândulas salivares labiais normais (18) e no epitélio tímico (25). Esta expressão da proteína p19 no epitélio tímico é muito importante, já que todas as células $T$ são continuamente ali formadas e, se as células epiteliais tímicas expressam a proteína p19 homóloga à proteína p19 (gag) do HTLV-1, existe uma real possibilidade de que células $T$ reativas contra a proteína p19 sejam formadas. No caso da expressão da proteína $\mathrm{p} 19 \mathrm{em}$ qualquer outro tecido, como detectado no tecido tireoideano normal e no tecido acometido pela doença auto-imune, células $\mathrm{T}$ existentes, reativas contra a proteína $\mathrm{p} 19$, podem se tornar células auto-reativas, no caso específico contra as células tireoideanas. A existência de uma possivel homologia compartilhada entre as proteínas $\mathrm{p} 19$ e gp21 expressas no tecido tireoideano e as proteínas p19 (gag) e gp21 (env) do HTLV-1 poderia explicar o início do processo auto-imune patológico no tecido tireoideano de um indivíduo geneticamente predisposto.

A diferença na mediana do percentual de positividade encontrada entre os grupos de intensidade de infiltração mononuclear, com maior percentual de positividade nos grupos de menor infiltração, talvez represente a predominância no número de células mononucleares sobre as células foliculares, pois quando existe maior infiltração mononuclear, o número de células foliculares é menor por campo avaliado e, como conseqüência deste número menor de células foliculares, uma menor positividade. Nada pode-se dizer a respeito de uma possível influência direta das células mononucleares sobre a expressão das proteínas p19 e gp21 no tecido tireoideano.

Devido ao alto percentual de positividade para as proteínas p19 e gp21 encontrado no tecido normal e no tecido acometido pela doença auto-imune, nós nos deparamos com a possibilidade real de reação cruzada e mimetismo molecular entre as proteinas p19 (gag) e gp21 (env) do HTLV-1 e as proteínas expressas no tecido tireoideano. Esta expressão pode representar a presença de seqüências genéticas do HTLV-1 incorpo- rada ao genoma do indivíduo (retrovirose endógena). A retrovirose endógena, que pode ativar a auto-imunidade patológica de várias formas (26) e a presença de proteínas do HTLV-1 no tecido tireoideano causando reação cruzada e mimetismo molecular, talvez possam estar envolvidos de forma direta ou indireta no desenvolvimento do processo auto-imune tireoideano nos indivíduos geneticamente predispostos, ou num "ambiente" geneticamente propício.

\section{AGRADECIMENTOS}

Os autores gostariam de agradecer às Dras. Andrea Rodrigues C. Pires e Maria Eugênia Leite Duarte pela ajuda na contagem das células e, Rita de Cássia Costa Cunha e Antônio Carlos dos Santos pela excelente assistência técnica. Também gostariamos de agradecer ao Departamento de Patologia da Universidade Federal Fluminense.

\section{REFERÊNCIAS}

1. MacLachian SM, Rapoport B. Genetlc factors in thyroid disease. In: Braverman LE, Utiger RD, editors. The Thyroid. Lippincott-Raven:Philadelphia, 1996:483-96.

2. Yamaguchi K, Mochizuki M, Watanabe T, Takatsuki K. Human T lymphotropic virus type 1 uveitis after Graves' disease. Br J Ophthalmol 1994;78:163-6.

3. Mizokami T, Okamura $K$, Kohno T, Sato $K$, Ikenoue $H$, Koruda $T$, et al. Human T-lymphotropic virus type 1 Associated uveitis in patients with Graves' disease treated with methylmercaptoimidazole. J Clin Endocrinol Metab 1995;80:1904-7.

4. Lagaye S, Vexiau P, Morozov V, Saal F, Gony J, Poorters AM, et al. Detection of HTLV-1 gag related sequences in leukocyte DNA from patients with polyendocrinopathies (Basedow-Graves' disease and insulin-dependent diabetes). C R Acad Sci Paris 1991:312:309-15.

5. Kawai $H$, Inui T, Kashiwagi S, Tsuchihashi T, Masuda K Kondo A, et al. HTLV-I infection in patients with autoimmune thyroiditis (Hashimoto's thyroiditis). J Med Virol 1992:38: 138-41.

6. Barret-Connor $E$. Is insulin-dependent diabetes mellitus caused by coxsackie virus B infection? Rev Infec Diseas 1985:7:207-15

7. Sultz HA, Hart BA, Zielezny M. Is mumps virus an aetiological factor in juvenile diabetes mellitus? J Pediatrics 1975:86:654-6.

8. Jaspan JB, Luo $\mathrm{H}$, Ahmed B, Tenenbaum $\mathrm{S}$, Voss $T$, Sander DM, et al. Evidence for a retroviral trigger in Graves' disease. Autoimmunity 1995:20:135-42.

9. Tran A, Quaranta JF, Beusnel C. Hepatitis C virus and Hashimoto's thyroiditis. Eur J Med 1992;1:116-8.

10. Tomer Y, Davies TF. Infection, thyroid disease, and autoimmunity. Endocr Rev 1993; 14:107-20. 
11. Norton AJ, Jordan S, Yeomans P. Brief, high-temperature heat denaturation (pressure cooking): a simple and effective method of antigen retrieval for routinely processed tissues. J Pathol 1994;173:371-9.

12. Kawai H, Mitsui T, Yokoi K, Akaike M, Hirose K, Hizawa K, et al. Evidence of HTLV-I in thyroid tissue in an HTLV-I carrier with Hashimoto's thyroiditis. J Mol Med 1996;74:275-8.

13. Mine $H$, Kawai $H$, Yokoi K, Akaike M, Saito S. High frequencles of human virus type I (HTLV-l) infection and presence of HTLV-II proviral DNA in blood donors with anti-thyroid antibodies. J Mol Med 1996:74:471-7.

14. Kubonishi I, Kubota T, Sawada T, Tanaka Y, Machida $\mathrm{H}$, Yoshida $O$, et al. An HTLV-I carrier with Graves' disease followed by uveitis: isolation of HTLV-I from thyroid tissue. Int J Hematol 1997;66:233-7.

15. Akamine H, Takasu N, Komiya I, Ishikawa K, Shinjyo T. Nakachi $K$, et al. Association of HTLV-I with autoimmune thyroiditis in patients with adult T-cell leukemia (ATL) and in HTLV-I carries. Clin Endocrinol (Oxf) 1996:45:461-6.

16. Brady JN. Biology of HTLV-l: host cell interactions. In: Höllsberg P. Hafler DA, eds. Human T-cell Lymphotropic Virus Type I. John Wiley \& Sons:West Sussex, 1996:79-1 12.

17. Kishi S, Saijyo S, Arai M, Karasawa S, Ueda S, Kannagi M, et al. Resistance to Fas-mediated apoptosis of peripheral $T$ cells in human T lymphocyte virus type I (HTLV-I) transgenic mice with autoimmune arthropathy. J Exp Med 1997; 186:57-64.

18. Shattles WG, Brookes SM, Venables PJW, Clark DA, Maini $R$. Expression of antigen reactive with a monoclonal antibody to HTLV-I p19 in salivary glands in Sjögren's syndrome. Clin Exp Immunol 1992;89:46-51.

19. Leib-Mösch C, Brack-Werner R, Werner T, Bachmann M, Faff $O$. Erfle $V$, et al. Endogenous retroviral elements in human DNA. Cancer Res 1990:50:5636s-42s.

20. Krieg AM, Gourley MF, Perl A. Endogenous retroviruses: potential etiological agents in autoimmunity. FASEB J 1992;6:2537-44
21. Brookes SM, Pandolfino YA, Mitchell TJ, Venables PJW, Shattles WG, Clark DA, et al. The immune response to and expression of cross-reactive retroviral gag sequences in autoimmune disease. $\mathrm{Br} \mathbf{J}$ Rheumatol 1992:31:735-42

22. Perl A, Rosenblatt JD, Chen SY, DiVincenzo JP, Bever R, Poiesz BJ, et al. Detection and cloning of new HTLV-1 related sequences in man. Nucl Acid Res 1989;7:6841-54

23. Banki K, Maced E, Hurley E. Human T-cell lymphotropic virus (HTLV) - related endogenous sequence, HRES- 1 , encodes a $28 \mathrm{Kda}$ protein: a possible autoantigen for HTLV-I gag-reactive autoantibodies. Proc Natl Acad Sci USA 1992;89:1939-43.

24. Ziegler B, Gay RE, Huang G, Fassbender HG, Gay S. Immunohistochemical localization of HTLV-I p19 and p24 related antigens in synovial joints of patients with rheumatoid arthritis. Am J Path 1989: 135:1-5.

25. Palker TJ, Singer KH, Vahlne A. Characterization of an antigen shared by human thymic epithelium and human T cell leukemia virus p19 gag protein. J Acq Imm Def Syndr Hum Retrovirol 1996; 11:10-9.

26. Nakagawa K, Harrison LC. The potential roles of endogenous retroviruses in autoimmunity. Immunol Rev $1996 ; 152: 193-236$

\section{Endereço para correspondência:}

Rubens A.C. Filho

Rua Visconde de Moraes 126/802

24.210-145 Niterói, RJ

FAX: (021) 704-5300

e.mail: radcf@microlink.com.br 